\title{
Travel attitudes or behaviours: Which one changes when they conflict?
}

\author{
Laura McCarthy $^{1} \cdot$ Alexa Delbosc $^{1}$ (D) $\cdot$ Maarten Kroesen ${ }^{2} \cdot$ Mathijs de Haas $^{3}$
}

Accepted: 21 September 2021 / Published online: 16 October 2021

(C) The Author(s), under exclusive licence to Springer Science+Business Media, LLC, part of Springer Nature 2021

\begin{abstract}
In recent years, there has been a resurgence of interest in the 'disagreement' or dissonance between travel attitudes and behaviours. This has shown that when people experience travel-related dissonance they are less satisfied with their travel experience. However, what remains unclear is whether people experiencing dissonance are more likely to change their travel attitude or their behaviour, so that they are more closely aligned. Moreover, it is unclear whether and how life events, such as having a child, interact with creating or reducing travel-related dissonance. Using data from a large and well-designed longitudinal study, this paper addresses these two gaps in the literature on travel-related cognitive dissonance through an exploratory study. The findings suggest that dissonant travellers are more likely to change their segment membership than consonant travellers. Furthermore, in line with the theory of cognitive dissonance, people may adjust either their attitudes or behaviours to achieve a state of consonance. This suggests that policymakers should not only focus on subtle nudges aimed at changing attitudes (and subsequently behaviours) in desirable directions but also on implementing policies aimed at directly influencing behaviours, assuming that attitudes will follow.
\end{abstract}

Keywords Cognitive dissonance $\cdot$ Travel behaviour $\cdot$ Life events

\section{Introduction}

Transportation researchers have long been interested in the relationship between attitudes and travel behaviour. Most of this research focuses on the congruent relationship between attitudes and behaviour, showing that positive mode-specific attitudes predict the use of that mode (Kroesen and Chorus 2018) or conversely that travel behaviours shape attitudes

Alexa Delbosc

alexa.delbosc@monash.edu

1 Department of Civil Engineering, Institute of Transport Studies, Monash University, 23 College Walk, Clayton, VIC 3800, Australia

2 Faculty of Technology, Policy and Management, TU Delft, Building 31. Jafalaan 5, 2628 BX Delft, The Netherlands

3 KiM Netherlands Institute for Transport Policy Analysis, Bezuidenhoutseweg 20, 2594 AV The Hague, The Netherlands 
(Tardiff 1977; Dobson et al. 1978; Kroesen et al. 2017). More recently, researchers have become interested in the state of 'disagreement' between attitudes and behaviours. When actions and attitudes do not match, people experience an unpleasant psychological state. In psychology, this state is referred to as cognitive dissonance and it has been a subject of research since the 1950s (Festinger 1957). When people experience cognitive dissonance, they tend to change either their attitude or their behaviour so that the two are more closely aligned.

In recent years transportation researchers have found that when people experience travel-related dissonance they are less satisfied with their travel experience (De Vos 2018). However, a recent review highlighted that to date no studies have been able to examine whether people change their travel behaviour to reduce travel-related dissonance (De Vos and Singleton 2020).

Furthermore, to date, no studies on travel-related dissonance have examined the role that life events might play in inducing (or reducing) a state of cognitive dissonance. The mobility biographies approach highlights the important role of life events, such as moving houses or changing jobs, in triggering travel behaviour change (Clark et al. 2016a; de Haas et al. 2018). For instance, moving house may allow an individual with negative attitudes towards the car but frequent car-use to move to a less car-dependent location. However, if the choice of home location is constrained, it may also induce dissonance, for example, if an individual who prefers transit must move to a car-dependent area for work (see for example the 'reverse causality hypothesis' between the built environment and travel, (van Wee et al. 2019)).

This paper attempts to address these two gaps in the literature on travel-related cognitive dissonance through an exploratory study. It does this through three research questions:

1. Over time, how stable is the state of travel-related cognitive dissonance?

2. Are people who experience travel-related cognitive dissonance more likely to change their travel behaviour or attitudes?

3. What is the impact of life events on inducing or reducing travel-related cognitive dissonance?

We explore these research questions using longitudinal panel data to examine whether mode-dissonant or mode-consonant individuals are more likely to remain in the same category in subsequent waves. Secondly, we explore whether mode-dissonant travellers are more likely to adapt their behaviour or attitudes to reduce dissonance. Finally, we explore the effect of life events on creating or reducing dissonance between travel attitudes and behaviours. Insights from these research questions may have implications for strategies encouraging travel behaviour change, identifying potential segments of the population who are more open to changing their travel behaviour.

\section{Cognitive dissonance theory and travel behaviour}

Cognitive Dissonance Theory (CDT) posits that people have an internal drive to resolve inconsistencies between attitudes and behaviours (Festinger 1957). If an inconsistency exists or arises between a particular attitude and behaviour, people will typically experience some level of psychological discomfort. In turn, this motivates people to adopt strategies to reduce this discomfort. Festinger (1957) outlined typical strategies 
to alleviate the discomfort: changing one of the dissonance conditions, changing the cognition through acquiring new knowledge that assists to alleviate the dissonance or trivialising the dissonance. For example, a person experiencing dissonance between his/her smoking behaviour and the cognition that smoking is bad for health may alter the behaviour (quit smoking) or the cognition (downplay the negative health effects of smoking). A priori, the theory of cognitive consistency assumes no dominance over which strategy is more likely to occur. Hence, based on this theory, an influence from behaviour towards attitudes is as likely as an influence from attitudes towards behaviour.

In the early days of social-psychological research, CDT was among the most heavily researched theories in the field. Literally hundreds of experiments have been conducted (Aronson 1992). Interestingly, however, little efforts have been made to operationalise the theory in a field setting. With respect to a particular target behaviour, one may identify four groups, two consonant ones and two dissonant ones, as depicted in Table 1 below. This approach to classifying people into categories of dissonant vs consonant has been used in studies of travel behaviour and residential location choice (Kroesen et al. 2017; Kamruzzaman et al. 2021). By assessing how membership of these four groups evolves, the main premise of CDT may already be tested in an observational setting, namely the notion that members of consonant groups are more likely to stay in their respective groups compared to members of the dissonant groups, who may be expected to either change their behaviour or their attitude towards the behaviour or adjust their circumstances. This approach assumes the adjustment of attitudes or behaviours is the only mechanism adopted to alleviate dissonance. Moreover, it does not account for the scale or variations in other background factors that may influence the extent and type of reduction strategies adopted. Nonetheless, this simplified approach allows for the fundamental concept of CDT to be tested in a field setting.

In this paper, we aim to return to the exploration of changes in attitude-behaviour inconsistencies over time, focusing on travel behaviour in particular. A few recent studies have explored this topic. Kroesen et al. (2017) used latent class analysis to identify groups of consonant and dissonant travellers and found, in line with CDT, that consonant travellers were less likely to change travel behaviour over time than dissonant travellers. De Vos (2018) also identified groups of consonant/dissonant travellers for different modes, revealing sizeable groups of dissonant travellers, especially regarding the use of the bicycle. The contribution of that study rests in the link that was made with travel satisfaction. In line with expectations, respondents travelling with their preferred travel mode (i.e., consonant travellers) seemed to experience their trip more positively compared to people travelling with a non-preferred travel mode (i.e., dissonant travellers). This result is well in line with CDT, in which inconsistency is assumed to create a state of stress/arousal, which can also be regarded as a state of dissatisfaction.

The present study also begins by classifying and describing consonant/dissonant travellers. However, this study extends the analysis to a second point in time to assess how stable these states are over time, and whether people are more likely to change their

Table 1 Four attitude/behaviour profiles

\begin{tabular}{lll}
\hline Attitude towards behaviour & \multicolumn{2}{l}{ Behavioural frequency } \\
\cline { 2 - 3 } & Low & High \\
\hline Negative & Consonant & Dissonant \\
Positive & Dissonant & Consonant \\
\hline
\end{tabular}


attitude or their behaviour to reduce dissonance. Given this is a major gap in the field, (identified in a recent review of CDT research (De Vos and Singleton 2020)), it represents the first contribution of this paper.

\section{Life events and cognitive dissonance}

The second contribution of this paper is to explore the relationship between life events and travel-related dissonance. The mobility biographies approach, first introduced by Lanzendorf (2003), provides a framework for understanding travel behaviour changes throughout the life course. The framework introduces the theory of multiple life domains and recognises that a change in one domain or area will have ramifications for other areas (Lanzendorf 2003). As comprehensive reviews of the state of the field and the development of the theoretical framework have recently been conducted (see Müggenburg et al. (2015) and Scheiner (2018)), we will instead focus this discussion on aspects of the framework relevant to our study.

A key concept emerging from the mobility biographies approach is the notion of stability and change in travel behaviour throughout the life course. Drawing on the role of habit as an important determinant of travel mode choice (Banister 1978; Aarts et al. 1997), the approach posits that life events, such as moving house or changing jobs, can disrupt stable travel routines. A life event can prompt changes to circumstances or context, which, in turn, requires an individual to switch from habitual to reflective thinking about their travel mode choices. It is these periods, in which travel routines are disrupted and habits are weakened, that provide a valuable opportunity to intervene and encourage the adoption of more sustainable travel choices (Verplanken et al. 2008).

Studies in this field have tended to focus on how behaviour, specifically mode use, changes following (or in anticipation of) a life event. Life events associated with an increase in car-based mobility include childbirth (Oakil et al. 2016; de Haas et al. 2018) and entering the workforce for the first time (Busch-Geertsema and Lanzendorf 2017). In contrast, life events associated with a decrease in car-based mobility are often associated with changes resulting in a reduction of income or change in activity patterns, such as unemployment or retirement (Oakil et al. 2014).

Overall, research in this field has shown that individuals are more likely to change their travel behaviour as a result of a life event than during stable circumstances (Clark et al. 2016b). A 'dissonant' life event may induce an inconsistency between the frequency of using a travel mode and the attitudes towards that travel mode. For instance, in the case of childbirth, cycling frequency may reduce but positive attitudes towards cycling may remain. Conversely, a dissonance-reducing life event may create an opportunity for an individual to align their travel mode use with their attitudes to that travel mode. For instance, an individual with positive attitudes towards public transport moving home from a cardependent location to a transit orientated location may reduce dissonance. It should be noted here that there are differing views regarding the hypothesized role of life events and inconsistencies between travel attitudes and behaviours. While Verplanken et al. (2008) posits that life events can prompt self-activation, enabling an individual to actively reflect on their optimal travel choices, applying cognitive dissonance theory, we are proposing that the life event may provide an opportunity to reconcile mismatches between travel attitudes and behaviours (rather than the self). 
Using the four profiles of dissonant/consonant travellers described in Table 1, we explore whether respondents who have experienced a life event between the two waves are more likely to transition into a different profile in the second wave. This analysis, which forms the second contribution of this paper, is largely exploratory.

\section{Methods}

\section{Data source}

The Netherlands Mobility Panel (knowns as the MPN) is an annual household panel survey that was set up to study the short-run and long-run dynamics in the travel behaviour of Dutch individuals and households, and to determine how changes in personal- and household characteristics, and in other travel-related factors, correlate with changes in travel behaviour (Hoogendoorn-Lanser et al. 2015). The first wave of data collection started in 2013 and the panel consists of approximately 2,000 complete households. Respondents are recruited by means of a screening questionnaire in which an adult household member is asked whether the whole household wants to participate in the MPN for several years. Yearly, after entering the panel, the same adult household member fills out a household questionnaire to gather basic information about the household. Furthermore, all household members of 12 years and older are asked to fill out an individual questionnaire and complete a three-day online travel diary. The individual questionnaire consists largely of questions that are repeated yearly. This includes questions regarding any life events that respondents have experienced in the previous 12 months. However, a special topic is repeated bi-annually. In the second and fourth waves of the MPN the special topic focused on attitudes and perceptions with regard to various modes of transportation. Therefore, the second (2014) and fourth (2016) waves of the MPN are used in this study. Table 2 presents basic demographics and life events among the survey sample.

In order to account for attrition and to maintain a representative sample, additional households are recruited yearly. In the second wave, additional focus was placed on recruiting certain groups (such as young and low educated people) since they were somewhat underrepresented in the first wave and had higher nonresponse levels. Due to attrition and recruitment of new households, there are some slight variations between waves in terms of sample composition. However, based on the so-called Gold Standard (which reflects the composition of the Dutch population on several personal- and household characteristics) it can be concluded that the sample is fairly representative for the Dutch population. The largest deviation is found on educational level, with an underrepresentation of low-educated people and an overrepresentation of high-educated people.

\section{Defining segment membership}

Table 3 presents the two measures used to determine segment membership: a composite measure of mode specific attitudes and the frequency of mode use. The measures derived from two sets of questions in the MPN survey. The MPN asks about attitudes towards travel by car, cycling and public transit. Six items are asked (Comfort/Relaxing/Saves time/Safe/ Flexible/Pleasurable) measured on a five-point Likert scale ranging from "Strongly Disagree" to "Strongly Agree". Cronbach's Alpha for all modes exceeded 0.8 (Table 3), indicating a sufficient level of internal consistency to allow for a composite score to be generated. 
Table 2 Descriptive statistics $(\mathrm{N}=3851$ wave pairs)

\begin{tabular}{|c|c|c|c|c|}
\hline & Variable & Category & $\%$ & $\mathrm{~N}$ \\
\hline \multirow[t]{13}{*}{ Demographics (2014) } & \multirow[t]{2}{*}{ Gender } & Male & 45 & 1785 \\
\hline & & Female & 54 & 2066 \\
\hline & \multirow[t]{3}{*}{ Age } & 29 years and younger & 20 & 771 \\
\hline & & 30 to 59 years & 56 & 2171 \\
\hline & & 60 years and older & 24 & 909 \\
\hline & \multirow[t]{5}{*}{ Employment status } & Employed & 59 & 2233 \\
\hline & & Job seeking/Incapacitated & 9 & 339 \\
\hline & & Retired or early retirement & 16 & 609 \\
\hline & & Student & 8 & 308 \\
\hline & & Housewife/husband & 8 & 312 \\
\hline & \multirow[t]{3}{*}{ Urbanisation level } & $\begin{array}{l}\text { Highly or very urbanized (1500 or more inhabit- } \\
\text { ants } / \mathrm{km}^{2} \text { ) }\end{array}$ & 46 & 1757 \\
\hline & & $\begin{array}{l}\text { Moderately urbanized (1000 to } 1500 \text { inhabitants/ } \\
\mathrm{km}^{2} \text { ) }\end{array}$ & 24 & 927 \\
\hline & & $\begin{array}{l}\text { Non-urbanized area (Less than } 1000 \text { inhabitants/ } \\
\mathrm{km}^{2} \text { ) }\end{array}$ & 30 & 1136 \\
\hline \multirow[t]{7}{*}{ Life events (2016) } & \multirow{7}{*}{$\begin{array}{l}\text { Respondents } \\
\text { experiencing a } \\
\text { life event }\end{array}$} & Child born in household & 3 & 98 \\
\hline & & Partnership dissolution & 1 & 48 \\
\hline & & Partnership formation & 1 & 55 \\
\hline & & Started or changed education programme & 4 & 139 \\
\hline & & Started working & 2 & 66 \\
\hline & & Stopped working & 3 & 116 \\
\hline & & New job & 9 & 354 \\
\hline
\end{tabular}

Table 3 Respondents' mode use and attitudes ( $\mathrm{N}=3851$ wave pairs $)$

\begin{tabular}{|c|c|c|c|c|c|c|}
\hline & \multicolumn{2}{|l|}{ Car } & \multicolumn{2}{|l|}{ Bicycle } & \multicolumn{2}{|c|}{ Public transport } \\
\hline & Wave 1 & Wave 2 & Wave 1 & Wave 2 & Wave 1 & Wave 2 \\
\hline \multicolumn{7}{|c|}{ Mode use [5 point scale, column percent shown here] } \\
\hline Less than 1 day per year/never (1) & 3.1 & 3.1 & 9.0 & 11.5 & 32.3 & 26.2 \\
\hline 1 to 11 days per year (2) & 4.5 & 4.5 & 8.6 & 8.2 & 34.0 & 31.6 \\
\hline 1 to 3 days per month (3) & 10.8 & 10.5 & 12.2 & 13.1 & 15.1 & 20.0 \\
\hline 1 to 3 days per week (4) & 36.0 & 36.3 & 25.8 & 26.0 & 9.7 & 12.4 \\
\hline 4 or more days per week (5) & 45.6 & 45.7 & 44.4 & 41.1 & 8.9 & 9.8 \\
\hline \multicolumn{7}{|l|}{ Attitude towards mode } \\
\hline Sum & 25.4 & 24.7 & 22.8 & 22.9 & 17.8 & 17.9 \\
\hline Standard deviation & 3.5 & 3.6 & 4.1 & 4.2 & 4.2 & 4.3 \\
\hline Cronbach's Alpha & 0.888 & 0.866 & 0.884 & 0.866 & 0.949 & 0.922 \\
\hline \multicolumn{7}{|c|}{ Composite attitude variable [5 point scale, column percent shown here] } \\
\hline Strongly disagree (1) & 0.1 & 0.1 & 0.9 & 0.9 & 3.2 & 3.4 \\
\hline Disagree (2) & 0.7 & 0.5 & 2.5 & 3.0 & 17.4 & 17.9 \\
\hline Neutral (3) & 10.4 & 10.6 & 20.3 & 19.3 & 55.4 & 54.5 \\
\hline Agree (4) & 59.5 & 57.0 & 59.2 & 58 & 22.6 & 22.2 \\
\hline Strongly Agree (5) & 29.3 & 31.7 & 17.1 & 18.9 & 1.3 & 2.0 \\
\hline
\end{tabular}


Scores for each of the six items were combined, creating a scale ranging from 6 to 30 . An average of the six items was then generated and rounded to the nearest integer, providing a value of between 1 and 5. The measure regarding mode use frequency derives from a question asking about frequency of car, public transport and bicycle use over the previous year. Responses were recoded to a five-point scale to align with the attitude measure.

The attitudinal measure does not directly align with more common psychological literature typically operationalising dissonance as an unpleasant feeling or tension. Nonetheless, cognitive dissonance theory explicitly states that people attempt to align their attitudes with behaviour. As such, the attitudinal measure we use in our study is still largely aligned with what CDT posits.

We used the two measures to categorise respondents into four groups based on their behaviour (frequent or infrequent) and attitudes (negative or positive). Each respondent was categorised into one of the four groups (Frequent-Positive; Frequent-Negative; Infrequent-Positive; Infrequent-Negative) for each mode (car, cycling and public transport). Respondents were categorised as "Infrequent" if they used the travel mode three days per month or less and "Frequent" if they used the travel mode at least weekly.

To allow a more equitable distribution of the four categories, respondents whose attitude towards a particular mode was a value of between 1 and 3 were classified as "Negative" and 4 or 5 as "Positive". Classifying respondents with neutral attitudes towards cycling and car in either the positive or negative category had a minimal bearing on the results. However, as a large number of respondents held neutral attitudes towards public transport, changing whether they were grouped in the positive or negative category lead to a significant change in the size of the consonant and dissonant segments for this mode. However, if "neutral" attitudes were re-classified as "positive" for public transport use, this resulted in multiple segments with very few respondents. Therefore we continued the analysis with all "neutral" responses coded as negative. While this approach is imperfect, and the public transport results must be treated with some caution, it ensures all segments are of a sufficient size to allow for meaningful analysis.

Table 4 shows the size of each segment and the percentage of respondents in each behaviour or attitudinal category. Overall, the largest segments among each of the three modes are consonant. Given the considerably lower frequency of public transport use compared with cycling and car use among respondents, the largest segment size in the Car and Cycle mode is Frequent-Positive, whereas among the Public Transport mode it is the Infrequent-Negative group. The Car model has the largest share of consonant respondents (81\%), followed by Cycling (76\%) and Public Transport (68\%).

Once the travellers were classified into consonant and dissonant groups, we conducted a logistic regression model that included initial segment membership for each of the modes. Seven life events were included and four exogenous variables (gender, employment status, age and location) as active covariates. The seven life events included: childbirth, partnership formation and dissolution, starting an education course, starting or stopping working and changing employment. 
Table 4 Indicators used to determine segment membership

\begin{tabular}{|c|c|c|c|c|c|c|c|c|c|c|c|c|}
\hline \multirow[t]{2}{*}{ Consonance } & \multicolumn{4}{|c|}{ Model 1: Car } & \multicolumn{4}{|c|}{ Model 2: Cycling } & \multicolumn{4}{|c|}{$\begin{array}{l}\text { Model 3: Public Trans- } \\
\text { port }\end{array}$} \\
\hline & $\mathrm{C}$ & $\mathrm{D}$ & $\mathrm{D}$ & $\mathrm{C}$ & $\mathrm{C}$ & $\mathrm{D}$ & $\mathrm{D}$ & $\mathrm{C}$ & $\mathrm{C}$ & $\mathrm{D}$ & $\mathrm{D}$ & $\mathrm{C}$ \\
\hline Name & FP & IP & $\mathrm{FN}$ & IN & FP & IP & FN & IN & FP & IP & FN & IN \\
\hline $\begin{array}{l}\text { Segment Size [row } \\
\text { percentage] }\end{array}$ & $76 \%$ & $13 \%$ & $7 \%$ & $5 \%$ & $61 \%$ & $15 \%$ & $9 \%$ & $15 \%$ & $7 \%$ & $19 \%$ & $13 \%$ & $61 \%$ \\
\hline \multicolumn{13}{|l|}{ Mode use (Time 1) } \\
\hline 1 day/year or less (1) & - & 11 & - & 20 & - & 15 & - & 41 & - & 19 & - & 32 \\
\hline 1-11 days/year (2) & - & 21 & - & 34 & - & 25 & - & 32 & - & 42 & - & 43 \\
\hline 1-3 days/month (3) & - & 69 & - & 46 & - & 60 & - & 28 & - & 40 & - & 25 \\
\hline 1-3 days/week (4) & 42 & - & 62 & - & 36 & - & 54 & - & 58 & - & 55 & - \\
\hline $4+$ days/week (5) & 58 & - & 38 & - & 64 & - & 46 & - & 42 & - & 45 & - \\
\hline \multicolumn{13}{|l|}{ Attitudes (Time 1) } \\
\hline Strongly disagree (1) & - & - & 0 & 3 & - & - & 0 & 6 & - & - & 3 & 5 \\
\hline Disagree (2) & - & - & 2 & 8 & - & - & 4 & 18 & - & - & 16 & 26 \\
\hline Neutral (3) & - & - & 98 & 90 & - & - & 96 & 76 & - & - & 82 & 69 \\
\hline Agree (4) & 62 & 80 & - & - & 71 & 91 & - & - & 91 & 92 & - & - \\
\hline Strongly agree (5) & 38 & 20 & - & - & 29 & 9 & - & - & 9 & 8 & - & - \\
\hline
\end{tabular}

Values within the table are percentages read down a given column. FP=Frequent use and positive attitude; $\mathrm{IP}=$ Infrequent use and positive attitude; $\mathrm{FN}=$ Frequent use and negative attitude; $\mathrm{IN}=$ Infrequent use and negative attitude; $\mathrm{C}=$ consonant; $\mathrm{D}=$ dissonant

\section{Results}

\section{Segment profiles}

Table 5 outlines the demographic characteristics of each of the twelve groups. As the characteristics of each segment is not the focus of this paper, these will not be discussed in detail. However, the profile of each segment is plausible. For example, those travellers typically comprising 'captive' transport markets, such as students (who are entitled to free public transit in The Netherlands), are underrepresented in the Frequent-Positive Car group but overrepresented in the Frequent-Negative Cycling and Public Transport Groups. This suggests that while members of these groups have a preference for car-based mobility, their current financial circumstances make car ownership unattainable and instead they use public transport or cycle. Similarly, Frequent Public Transport users, both negative and positive, are overrepresented in highly urbanised locations and underrepresented in rural locations, likely reflecting the different level of public transport service in the respective locations.

\section{Stability of travel-related cognitive dissonance}

Table 6 shows the movements between groups between Wave 1 (2014) and 2 (2016) for car, cycling and public transit modes respectively. Given earlier research (Kroesen et al. 
Table 5 Demographic characteristics respondents, Wave 1 (2014)

\begin{tabular}{|c|c|c|c|c|c|c|c|c|c|c|c|c|c|}
\hline \multirow[t]{2}{*}{ Segment } & \multicolumn{4}{|l|}{ Car } & \multicolumn{4}{|c|}{ Cycling } & \multicolumn{4}{|c|}{ Public Transit } & \multirow{2}{*}{$\begin{array}{l}\text { Sample } \\
-\end{array}$} \\
\hline & FP & IP & FN & IN & FP & IP & FN & IN & FP & IP & $\mathrm{FN}$ & IN & \\
\hline Consonant & $\mathrm{C}$ & $\mathrm{D}$ & D & $\mathrm{C}$ & $\mathrm{C}$ & D & D & $\mathrm{C}$ & $\mathrm{C}$ & D & $\mathrm{D}$ & $\mathrm{C}$ & - \\
\hline $\begin{array}{l}\text { Seg- } \\
\text { ment Size [row } \\
\text { percentage] }\end{array}$ & $76 \%$ & $13 \%$ & $7 \%$ & $5 \%$ & $61 \%$ & $15 \%$ & $9 \%$ & $15 \%$ & $7 \%$ & $19 \%$ & $13 \%$ & $61 \%$ & $100 \%$ \\
\hline
\end{tabular}

\begin{tabular}{|c|c|c|c|c|c|c|c|c|c|c|c|c|c|}
\hline \multicolumn{14}{|l|}{ Gender } \\
\hline Male & 49 & 35 & 39 & 41 & 44 & 53 & 43 & 53 & 50 & 46 & 42 & 47 & 45 \\
\hline Female & 51 & 65 & 61 & 59 & 56 & 47 & 57 & 47 & 50 & 54 & 58 & 53 & 54 \\
\hline \multicolumn{14}{|l|}{ Age } \\
\hline Under 30 & 17 & 39 & 11 & 27 & 20 & 15 & 33 & 17 & 42 & 12 & 55 & 15 & 20 \\
\hline 30 to 59 & 61 & 40 & 52 & 49 & 55 & 65 & 51 & 64 & 41 & 51 & 37 & 65 & 56 \\
\hline 60 years + & 22 & 21 & 37 & 24 & 25 & 19 & 16 & 19 & 17 & 37 & 08 & 20 & 24 \\
\hline \multicolumn{14}{|l|}{ Location } \\
\hline High urban & 41 & 65 & 51 & 66 & 47 & 41 & 46 & 45 & 65 & 48 & 59 & 44 & 59 \\
\hline Med urban & 26 & 20 & 18 & 21 & 25 & 23 & 25 & 22 & 19 & 23 & 23 & 24 & 09 \\
\hline Non-urban & 34 & 15 & 31 & 13 & 28 & 36 & 29 & 34 & 16 & 29 & 18 & 32 & 16 \\
\hline \multicolumn{14}{|l|}{ Employment } \\
\hline Employed & 64 & 44 & 50 & 47 & 58 & 71 & 48 & 67 & 54 & 51 & 47 & 67 & 08 \\
\hline Unemployed & 08 & 14 & 07 & 16 & 08 & 10 & 12 & 08 & 08 & 08 & 08 & 10 & 08 \\
\hline Retired & 15 & 14 & 26 & 17 & 16 & 14 & 10 & 13 & 11 & 28 & 05 & 13 & 46 \\
\hline Studying & 06 & 19 & 06 & 13 & 09 & 02 & 21 & 05 & 24 & 04 & 37 & 03 & 24 \\
\hline Homemaker & 08 & 09 & 11 & 08 & 09 & 04 & 08 & 07 & 03 & 09 & 03 & 08 & 30 \\
\hline
\end{tabular}

Values within the table are percentages read down a given column. FP=Frequent use and positive attitude; $\mathrm{IP}=$ Infrequent use and positive attitude; $\mathrm{FN}=$ Frequent use and negative attitude; $\mathrm{IN}=$ Infrequent use and negative attitude; $\mathrm{C}=$ consonant; $\mathrm{D}=$ dissonant

Table 6 Movements between segments (Waves 1 and 2)

\begin{tabular}{|c|c|c|c|c|c|c|c|c|c|c|c|c|c|c|c|}
\hline & \multirow{4}{*}{ Size } & \multicolumn{4}{|c|}{ Car $(\%)$} & & \multicolumn{4}{|c|}{ Cycling (\%) } & & \multicolumn{4}{|c|}{ Public Transport (\%) } \\
\hline & & \multicolumn{4}{|c|}{2014 (Wave 1) } & & \multicolumn{4}{|c|}{2014 (Wave 1) } & & \multicolumn{4}{|c|}{2014 (Wave 1) } \\
\hline & & $76 \%$ & $13 \%$ & $7 \%$ & $5 \%$ & & $61 \%$ & $15 \%$ & $9 \%$ & $15 \%$ & & $7 \%$ & $19 \%$ & $13 \%$ & $61 \%$ \\
\hline & & FP & $I P$ & $F N$ & IN & & FP & $I P$ & $F N$ & IN & & $\mathbf{F P}$ & $I P$ & $F N$ & IN \\
\hline \multirow[t]{4}{*}{2016 (Wave 2) } & FP & 89 & 35 & 53 & 15 & FP & 83 & 25 & 43 & 12 & FP & 38 & 12 & 10 & 2 \\
\hline & $I P$ & 6 & 53 & 5 & 28 & $I P$ & 8 & 51 & 8 & 22 & $I P$ & 30 & 48 & 7 & 11 \\
\hline & $F N$ & 5 & 4 & 34 & 14 & $F N$ & 6 & 4 & 32 & 8 & $F N$ & 16 & 7 & 42 & 13 \\
\hline & IN & 1 & 8 & 8 & 43 & IN & 3 & 21 & 18 & 58 & IN & 16 & 32 & 41 & 74 \\
\hline
\end{tabular}

Values within the table are percentages read down a given column. Bold indicates consonant segment, italics indicate dissonant segment

2017), we would expect the consonant segments to be the most stable (and have the highest probability of remaining in the same segment in the second wave) and the dissonant segments to be the least stable. This is the case for the largest consonant segments within each mode. Approximately $89 \%$ of the FP Car segment remained in the same segment in Wave 
2 with similar proportions for the FP Cycling (83\%) and IN Public Transit segments (74\%). However, the smallest consonant segments (IN Car, IN Cycling and FP Public Transit) were less likely to remain in the same segment in the second wave. This is likely due to forming a much smaller proportion of the sample (5\% car; $15 \%$ cycling; $7 \%$ PT) and, as such, slight changes (which may in part be random, e.g. when resulting from random from measurement errors) may appear more pronounced.

Interestingly, across all modes, dissonant travellers were more likely to remain in the Infrequent-Positive segment between waves than their counterparts in the Frequent-Negative dissonant segment. For instance, approximately half of the 2014 IP segment for car (53\%), cycling (51\%) and public transport (48\%) remained in this state in 2016. In contrast, the proportion of respondents remaining in the Frequent-Negative segments between waves was $34 \%$ (car), 32\% (cycling) and $42 \%$ (public transport). This suggests infrequent use and positive attitudes are perhaps less of a motivator to reduce dissonance than frequent use and negative attitudes.

These findings address the first research question of this paper. The next section explores whether people who experience travel-related cognitive dissonance are more likely to change their travel behaviour or their attitudes.

\section{Change in behaviour and attitudes among formerly dissonant travellers}

A core aim of this paper was to explore whether respondents experiencing travel-related cognitive dissonance more likely to change their travel behaviour or attitudes. To explore this, we assessed the movements between segments, between waves. Respondents in one of the dissonant segments in 2014 (either 'Frequent-Negative' or 'Infrequent-Positive') could transition into a consonant segment in 2016 by adjusting either their attitudes or their behaviour.

We would expect Frequent Negative travellers to be travelling against their attitudes due to external factors, such as poor transport infrastructure or conceivably time, income or family limitations. As such, we would expect an adjustment in attitudes in order to move to a consonant group (FP). Interestingly, however, whether respondents in a dissonant segment changed their attitude or behaviour varied depending on the mode and their original segment (see Table 7).

For both car travel and cycling, people who were IP in 2014 were more likely to change their behaviour than their attitude to become consonant travellers. Over $80 \%$ of IP drivers in 2014 who became consonant in 2016 did so because they drove more in 2016; 54\% of IP

Table 7 Change in behaviour vs. attitude for people who moved from dissonant to consonant segment between Waves 1 and 2

\begin{tabular}{llll}
\hline 2014 dissonant segment & Mode & \multicolumn{2}{c}{\begin{tabular}{l} 
of respondents \\
\cline { 3 - 4 }
\end{tabular}} \\
& & $\begin{array}{l}\text { Changing } \\
\text { behaviour }\end{array}$ & $\begin{array}{l}\text { Chang- } \\
\text { ing } \\
\text { attitude }\end{array}$ \\
\hline Infrequent positive & Car & 81 & 19 \\
& Cycling & 54 & 46 \\
Frequent negative & Public transport & 27 & 73 \\
& Car & 13 & 87 \\
& Cycling & 30 & 70 \\
& Public transport & 80 & 20 \\
\hline
\end{tabular}


cyclists did the same. In contrast, FN drivers and cyclists in 2014 who became consonant in 2016 were more likely to change their attitudes; $87 \%$ of $\mathrm{FN}$ drivers and $70 \%$ of cyclists who changed classification did so because they had a more positive attitude to the respective modes in 2016.

The pattern was reversed for public transport. Here, $73 \%$ of IP transit users who became consonant between 2014 and 2016 did this by reducing their attitude to public transport, becoming IN users. Among the FN public transport riders who became consonant in 2016, $80 \%$ did this by reducing their ridership (becoming IN).

These contrasting patterns may be explained by the baseline attitudes toward the three modes and considerably lower use of public transport among the sample. Overall attitudes toward cars and bicycles are more positive than public transport and only $20 \%$ of respondents are categorised as 'frequent' public transport users compared with $83 \%$ of car travellers and $70 \%$ of cyclists.

The final section of the findings addresses the third research question, exploring whether life events induce or reduce travel-related cognitive dissonance.

\section{Life events and changes in dissonance}

Table 8 presents the results of paired sample t-tests showing the changes in mean attitudes and behaviour between 2014 and 2016. The changes are presented overall and by respondents who have experienced a life event. It should be noted that these are derived from ordinal scales and no correction was made for multiple comparisons; however these initial results provide an indication of the direction of change between survey waves. Among the overall sample, there are marginally significant declines in cycling and increases in public transit use. There were no significant changes to attitudes towards each mode between the survey years. Interestingly, among the life events examined, only behaviour changes are significant suggesting that when experiencing a life event, behavioural rather than attitudinal changes create dissonance. However, as we are examining the aggregate changes this may mask changes apparent within individual groups.

Most life events analysed were associated with some behaviour change between the two survey years. Echoing findings from previous studies examining the effects of different life events on travel mode use, childbirth is associated with a slight decline in cycling (de Haas et al. 2018). Of note, partnership formation is associated with an increase in car-use and decrease in cycling. This is likely attributed to the new partner owning a vehicle and, as a result, more joint trips being conducted by car rather than cycling. An alternative interpretation could also be, however, that it is more cost-efficient to own a vehicle as couple, and, as a result respondents may have been more likely to purchase a vehicle in the intervening two years between the survey waves. Starting and stopping working is associated with an increase and decrease in car use, respectively. Stopping working is also associated with an increase in public transit use. These mode changes are likely a result of income or timebudget changes, as a result of changing employment status.

Starting an education course is associated with a decrease in cycling. This may reflect the local context, as in The Netherlands students can travel for free on public transport to and from their education institution. Finally, changing jobs (but not changing job location) is associated with an increase in car use and decrease in public transport use. This could reflect gaining a promotion and a subsequent increase in salary or obtaining a company car.

Table 9 presents the results of a logistic regression model that included initial segment membership for each of the modes and shows the probabilities of changing segments 


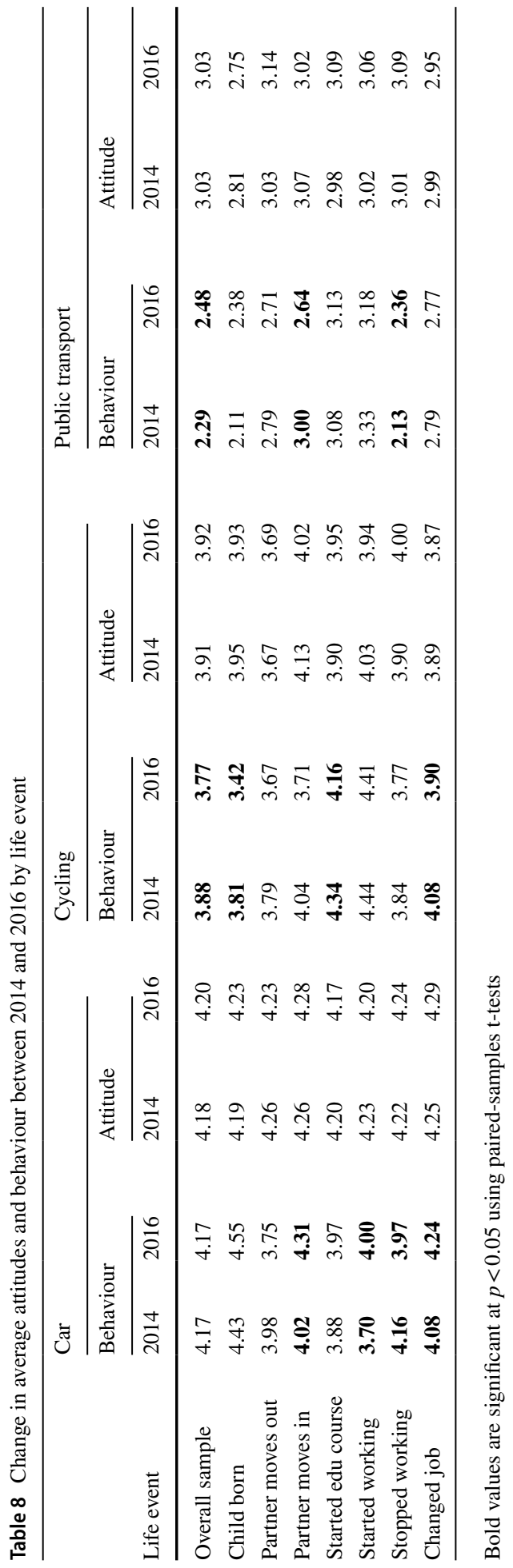




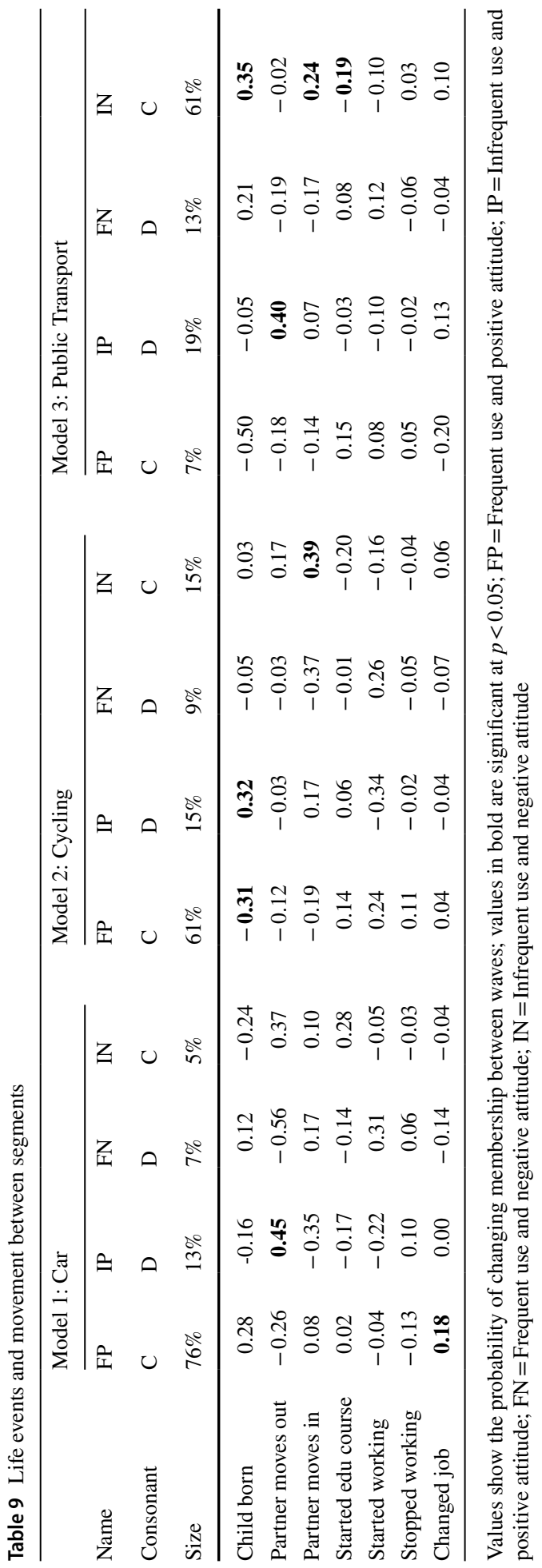


between 2014 and 2016 by type of life event. The results have been presented in this format rather than logit parameters for easier interpretation. Statistically significant movements between segments were evident among respondents who have experienced childbirth, partnership formation and dissolution, starting an education course and changing employment or employment location. However, across all life events and modes, respondents were equally likely to become either more consonant or more dissonant following a life event.

Of note, childbirth was associated with a greater likelihood of forming part of the IP Cycling segment and a lower likelihood of forming part of the FP Cycling segment. This reflects the decline in cycling evident in Table 6 and echoes previous research showing new parenthood is associated with a decline in cycling (Scheiner and Holz-Rau 2013; de Haas et al. 2018). Interestingly, childbirth is also associated with an increasing likelihood of forming part of the IN Public Transit segment. As public transit is commonly used for commuting, this may reflect the changes in activity patterns as result of taking parental leave and reduced use of this mode for work travel.

Partnership formation and dissolution were associated with slight movements between the segments. Partnership dissolution was associated with an increased likelihood of forming part of the IP Car and IP PT segment. In contrast, partnership formation increased the likelihood of forming part of the IN Cycling and PT segments. These changes could be attributed to the new partner bringing a car to the household (or, in the case of dissolution, taking away a car). Among respondents who experienced a partnership formation, vehicle ownership increased from 0.8 vehicles per household to 1.0 vehicles per household (compared to a slight decline in vehicle ownership across the entire survey sample). This suggests the new partner may bring a vehicle to the relationship or they may be more likely to purchase a new vehicle as a couple, with subsequent implications for the respondents' daily travel behaviour.

Starting an education course is associated with a decreased likelihood of forming part of the Infrequent-Negative PT segment and increased likelihood of forming part of either Frequent Positive or Frequent Negative PT segment (although the latter two changes are not significant). This likely reflects the growth of public transit use during tertiary study and provision of reduced fares available to students.

Finally, the two employment life events were associated with only marginal movements between segments. Changing job was associated with a greater likelihood of forming part of the FP Car segment while changing job location was associated with a greater likelihood of forming part of the IN PT segment and a less likely to form part of the FP PT segment.

For some life events the results are difficult to interpret. Perhaps this is because the life event is not captured at a sufficiently granular level. For instance, life events resulting in location changes (such as moving house, changing jobs or changing job locations) will likely have varying effects depending on the spatial and temporal context of the change. Surprisingly, no significant effects were evident for starting or stopping employment.

\section{Discussion and conclusion}

This paper explored stability among dissonant and consonant travellers and whether dissonant travellers are more likely to adjust their behaviour or attitudes to reach a state of consonance. Moreover, it explored the role of life events in creating or reducing dissonance between travel attitudes and behaviours. Differences between travel attitudes and behaviour 
were explored by public transit, cycling and car use, using panel data. It should be noted there are limitations regarding the measure we used to assess dissonance and the dissonance strategies we tested (only behaviour or attitude change). The psychology literature has identified a range of other mechanisms to reduce dissonance, such as self-forgiving, denial of responsibility or forgetting about the dissonance (Kruglanski et al. 2018), that depend on the intensity of negative feeling and familiarity of the situation (Cancino-Montecinos et al. 2020). In a travel behaviour context, it is plausible people could adopt a range of these and other strategies to reduce dissonance. The implications of this limitation are discussed below.

Addressing our first research question, consistent with earlier research (Kroesen et al. 2017), between the survey years, dissonant travellers were more likely to change their segment membership than consonant travellers. Interestingly, dissonant travellers were more likely to remain in the Infrequent-Positive segment between waves than travellers in the Frequent-Negative segment. This suggests that infrequent use and positive attitudes are perhaps less cognitively distressing than frequent use and negative attitudes. This may be evidence that people are practicing a range of mental mechanisms to reduce this dissonance, such as self-forgiving or denial of responsibility (e.g. 'I'd love to cycle but it's not my fault it isn't safe) (Kruglanski et al. 2018).

Should this indeed be true, then a straightforward implication for policy would be that positive attitudes, e.g. towards bicycle use, are not enough to increase the uptake of cycling. Instead, policies that negatively influence the attitudes towards alternative modes (e.g. the car) may potentially be more effective. Similarly, encouraging an increase in behavioural frequency for certain modes (e.g. encouraging infrequent-negative cyclists to cycle more frequently), may lead to more positive attitudes towards this mode.

In addition, from a scientific perspective, it would be interesting to explore whether dissonance resulting from infrequent use and positive attitudes is indeed less distressing than dissonance resulting from frequent use and negative attitudes. As shown by De Vos (2018) dissonance between the chosen and preferred mode also translates itself into travel dissatisfaction. This concept could be used to assess whether those belonging to the segment "frequent use and negative attitudes" are (even) more dissatisfied with their travel behaviour than those belonging to the segment "infrequent use and positive attitudes".

Our second research question explored whether dissonant travellers were more likely to adjust their behaviour or attitudes. The results depended on the mode and their original class. A similar pattern was evident between car and cycling modes. Infrequent car travellers and cyclists with positive attitudes were more likely to increase their use than adjust their attitudes to reach a state of consonance in the following wave. Conversely, among frequent car-users and cyclists with negative attitudes, their attitudes were likely to become more favourable in the following wave. The reverse picture was evident for public transport; this is likely to be attributed to the baseline use and attitudes towards this mode being considerably lower than for car and cycling.

A general take-way from the results above is that, in line with the theory of cognitive dissonance, people may adjust both their attitudes and behaviours to achieve a state of consonance. From a policy perspective, this means that policymakers should not only focus on subtle nudges aimed at changing attitudes (and subsequently behaviours) in desirable directions but may also implement policies that aim to directly influence behaviours, e.g. by setting rules or pricing policies, assuming that attitudes will follow.

Finally, we explored whether life events induced or reduced dissonance. Nearly all of the life events included in the analysis were associated with changing levels of cognitive dissonance across at least one travel mode. However, across all life events participants were 
equally likely to become more or less consonant following a life event. And while certain life events were associated with behavioural changes between the two survey years, no life events were associated with attitudinal changes towards the travel mode. This suggests that following life events, behavioural rather than attitudinal changes tend to create dissonance. Future analysis, using data from subsequent waves, could explore whether there is a lag in attitude change following the behavioural change.

Life events associated with an increase in car-based mobility (either as a result of increasing car-use or decreasing use of cycling or public transit) included: childbirth, moving in with a partner, starting work and changing jobs. An increase in car-use, over time, is likely to contribute to the adoption of more favourable attitudes towards car-use. This, in turn, makes it less likely individuals will return to their former sustainable travel patterns, if, or when, their circumstances change. The adoption of more favourable attitudes towards car-use poses problems for transportation planners and policymakers seeking to encourage more sustainable travel modes. Further qualitative research may assist in unpicking the processes by which travel attitudes are adjusted (or not) to align with new travel behaviours. This would provide important insights to contribute to policies tasked at curbing the adoption of car-based mobility associated with certain life events.

Although the panel data provides a rich and detailed source of life events, several limitations exist. Due to the small number of respondents experiencing certain life events, some of the results were difficult to interpret. Furthermore, the classification of life events, especially those that instigated a relocation of work or home location, could be analysed at a more granular level. As data from future years becomes available, and more participants experience these life events, this will assist with interpreting the changing levels of cognitive dissonance associated with experiencing less common life events.

Further limitations regard the measures and classification process we adopted. As this was an exploratory analysis, we conducted an a priori classification. However, future analyses could adopt a post-hoc classification process which may yield more nuanced segments of behavioural and attitudinal adjustments made by dissonant travellers. Moreover, we assumed travellers were only to reach a consonant state through adjusting their attitudes or behaviours where we have acknowledged that multiple strategies (such as forgetting or trivialising) may also be adopted (Kruglanski et al. 2018). In addition, we did not account for the magnitude of the dissonance or familiarity of the situation in influencing the dissonance reduction strategy adopted (Cancino-Montecinos et al. 2020). As this was an exploratory study, aiming to test fundamental concepts of CDT, these topics are proposed for future research.

The panel data used in this analysis was conducted before the COVID-19 pandemic. Given the anticipated structural changes to employment practices prompted by the pandemic, it may provide an opportunity for respondents to reconcile disparities between their travel attitudes and behaviour. For instance, respondents in the 'Frequent-Negative' categories for car or public transport may have the opportunity to work from home, reducing the need for commuting. Initial analysis of MPN respondents suggests that, of those respondents working at home during the pandemic, over a quarter expect to work from home more in the future (de Haas et al. 2020). Data from future waves will reveal the extent that this has transpired into changing travel practices and the subsequent impact this may have on reducing travel related cognitive dissonance.

Author contribution Laura McCarthy: Research conception, research design, data analysis, results interpretation, lead paper writing. Alexa Delbosc: Research design, results interpretation, paper writing. Maarten 
Kroesen: Research design, results interpretation, paper writing. Mathijs de Haas: Data analysis, paper writing.

\section{Declarations}

Conflict of interest On behalf of all authors, the corresponding author states that there is no conflict of interest.

\section{References}

Aarts, H., Verplanken, B., Van Knippenberg, A.: Habit and information use in travel mode choices. Acta Physiol. (oxf.) 96(1-2), 1-14 (1997)

Aronson, E.: The return of the repressed: dissonance theory makes a comeback. Psychol. Inq. 3(4), 303-311 (1992)

Banister, D.: Influence of habit formation on modal choice-a heuristic model. Transportation 7(1), 5-18 (1978)

Busch-Geertsema, A., Lanzendorf, M.: From university to work life-jumping behind the wheel? Explaining mode change of students making the transition to professional life. Transp. Res. Part a: Policy Pract. 106, 181-196 (2017)

Cancino-Montecinos, S., Björklund, F., Lindholm, T.: A general model of dissonance reduction: unifying past accounts via an emotion regulation perspective. Front. Psychol. 11, 540081 (2020)

Clark, B., Chatterjee, K., Melia, S.: Changes in level of household car ownership: the role of life events and spatial context. Transportation 43, 565-599 (2016a)

Clark, B., Chatterjee, K., Melia, S.: Changes to commute mode: the role of life events, spatial context and environmental attitude. Transp. Res. Part a: Policy Pract. 89, 89-105 (2016b)

de Haas, M.C., Scheepers, C.E., Harms, L.W.J., Kroesen, M.: Travel pattern transitions: applying latent transition analysis within the mobility biographies framework. Transp. Res. Part a: Policy Pract. 107, 140-151 (2018)

de Haas, M., Faber, R., Hamersma, M.: How COVID-19 and the Dutch 'intelligent lockdown' change activities, work and travel behaviour: evidence from longitudinal data in the Netherlands. Transp. Res. Interdiscip. Perspect. 6, 100150 (2020)

De Vos, J.: Do people travel with their preferred travel mode? Analysing the extent of travel mode dissonance and its effect on travel satisfaction. Transp. Res. Part a: Policy Pract. 117, 261-274 (2018)

De Vos, J., Singleton, P.A.: Travel and cognitive dissonance. Transp. Res. Part a: Policy Pract. 138, 525-536 (2020)

Dobson, R., Dunbar, F., Smith, C.J., Reibstein, D., Lovelock, C.: Structural models for the analysis of traveler attitude-behavior relationships. Transportation 7(4), 351-363 (1978)

Festinger, L.: A theory of cognitive dissonance. Stanford University Press, Stanford, CA (1957)

Hoogendoorn-Lanser, S., Schaap, N.T.W., OldeKalter, M.-J.: The Netherlands mobility panel: an innovative design approach for web-based longitudinal travel data collection. Transp. Res. Procedia 11, 311-329 (2015)

Kamruzzaman, M., Giles-Corti, B., De Vos, J., Witlox, F., Shatu, F., Turrell, G.: The life and death of residential dissonants in transit-oriented development: a discrete time survival analysis. J. Transp. Geogr. 90, $102921(2021)$

Kroesen, M., Chorus, C.: The role of general and specific attitudes in predicting travel behaviour-a fatal dilemma? Travel Behav. Soc. 10, 33-41 (2018)

Kroesen, M., Handy, S., Chorus, C.: Do attitudes cause behavior or vice versa? An alternative conceptualization of the attitude-behavior relationship in travel behavior modeling. Transp. Res. Part a: Policy Pract. 101, 190-202 (2017)

Kruglanski, A.W., Jasko, K., Milyavsky, M., Chernikova, M., Webber, D., Pierro, A., Di Santo, D.: Cognitive consistency theory in social psychology: a paradigm reconsidered. Psychol. Inq. 29(2), 45-59 (2018)

Lanzendorf, M.: Mobility biographies. A new perspective for understanding travel behaviour. In: 10th International Conference on Travel Behaviour Research (IATBR). Lucerne (2003) 
Müggenburg, H., Busch-Geertsema, A., Lanzendorf, M.: Mobility biographies: a review of achievements and challenges of the mobility biographies approach and a framework for further research. J. Transp. Geogr. 46, 151-163 (2015)

Oakil, A.T.M., Ettema, D., Arentze, T., Timmermans, H.: Changing household car ownership level and life cycle events: an action in anticipation or an action on occurrence. Transportation 41(4), 889-904 (2014)

Oakil, A.T.M., Manting, D., Nijland, H.: Dynamics in car ownership: the role of entry into parenthood. Eur. J. Transp. Infrastruct. Res. 16(4), 661-673 (2016)

Scheiner, J.: Why is there change in travel behaviour? In search of a theoretical framework for mobility biographies. Erdkunde 72(1), 41-62 (2018)

Scheiner, J., Holz-Rau, C.: A comprehensive study of life course, cohort, and period effects on changes in travel mode use. Transp. Res. Part a: Policy Pract. 47, 167-181 (2013)

Tardiff, T.J.: Causal inferences involving transportation attitudes and behavior. Transp. Res. 11(6), 397-404 (1977)

van Wee, B., De Vos, J., Maat, K.: Impacts of the built environment and travel behaviour on attitudes: theories underpinning the reverse causality hypothesis. J. Transp. Geogr. 80, 102540 (2019)

Verplanken, B., Walker, I., Davis, A., Jurasek, M.: Context change and travel mode choice: Combining the habit discontinuity and self-activation hypotheses. J. Environ. Psychol. 28(2), 121-127 (2008)

Publisher's Note Springer Nature remains neutral with regard to jurisdictional claims in published maps and institutional affiliations.

Laura McCarthy currently works for the New Zealand Ministry of Transport. In 2019, she completed her $\mathrm{PhD}$ at Monash University. Her PhD explored the effects of life events, and specifically parenthood, on travel behaviour with a particular focus on public transit use.

Dr Alexa Delbosc is a Senior Lecturer at the Monash University Institute of Transport Studies in the Department of Civil Engineering. She draws from her background in social psychology and transport to study the intersection between the transport system, individual travel and societal quality of life. She teaches traffic engineering and management at Monash University with an emphasis on managing the system for the needs of all road users.

Dr Maarten Kroesen is an Associate Professor in Travel Behaviour Research at the Faculty of Technology Policy and Management at Delft University of Technology, the Netherlands. His research focuses on active modes, particularly in relation to health and uncovering complex causal structures using panel data.

Mathijs de Haas is a researcher at the Netherlands Institute for Transport Policy Analysis (KiM) and a PhD student at the Delft University of Technology. His main research topic is person mobility, with a focus on active modes (walking and cycling). Using longitudinal data, he studies causal processes underlying travel behavior change. Recent work includes studies on substitution effects of the e-bike and causal relations between body-mass index, self-rated health and active modes. Currently, he is studying the effects of COVID-19 on the (causal) relationships between attitudes and travel behavior. 